\title{
Think Big: The Evolution of Bureaucracy
}

\begin{abstract}
As the university or research library (university library with pretentions) grows it loses sight of any object for existence except existence itself. In the end it collects as much as it can and selects little or nothing, stultifying its own index(es). It comes to exist for everyone and no one. That is a fault, and much of the fault lies in the wrong choice of an organizational model as well as to the temper of the time.
\end{abstract}

$\mathrm{T}$ HERE Is an admirable article in the Summer 1970 issue of Library Resources \& Technical Services titled "Acquisition Policy for University Libraries: Selection or Collection" by Betty J. Meyer and John T. Demos. It is an almost bald expression of the idea that the research library is something which exists for its own sake. Jacques Barzun has remarked that some time ago when one met someone at a party and he announced that he was doing research, one would ask what the research was on or in. Now we just congratulate him. But here I am not so concerned with the idea of research as something good in itself, but with the idea that a research library is good because it is a research library.

Let me borrow another popular image and speak of the evolution of the library. Libraries usually start (or did) with some purpose-as a collection of material to serve the ends of a person or organization. Perhaps it is the literate members of a community, or the teach-

Mr. Horn is reference librarian and bibliographer at Clarion State College Library, Clarion State College, Clarion, Pennsylvania. ers and students in a school, or the people who work in some company. The significant fact is that they all need a library. It is possible and even common to start off not needing what is in the library (the library as ornament), but that is a bad start and let it pass for now. Let us assume that we are thinking about a situation in which the contents of libraries are needed. The library will probably be small and so will its group of users. Indeed, the users will have a commonality of interest and the library will reflect that interest.

If the community and library grow, or if the library suddenly expands, the situation becomes confused. Permit me to use college and university libraries to illustrate, for I am more familiar with them than with other kinds of libraries. Take the example of a library in a medium-sized college or small university where there is no longer a true community of users. There are many different departments, and they all have their particular set of needs and requests to present. At the same time the librarians begin to acquire greater authority, for even if the library is run by a faculty committee, the librarians will interpret the rulings of the committee and execute its orders within the constraints of 
the total situation, especially of the library budget.

The role of the library organization is also important. What structure will gradually evolve? Will there be $a$ librarian with assistants, or will the library begin to develop a faculty of its own? All too often the former is the case. Too many library staffs have developed along autocratic rather than democratic lines. One librarian possesses most of the power; he will likely be the only librarian recognized as a member of the faculty; all the rest will be job-holders with him or her as their boss.

The next stage of evolution is the point at which a medium-sized university or college is on the verge of becoming a university. Here the library will be a semi-autonomous organization very much concerned with balancing off the collection. Now more concern will be expressed about anticipating potential research interests. Diversification becomes the watchword; collecting in hitherto dormant or nonexistent fields becomes evident; future needs become today's necessities.

Libraries as we all know cannot be run by committees, anymore than can universities. The library organization will mirror the organizational structure of the university more and more. The chief library administrator is likely at this stage, if not earlier, to become the director of libraries. That is to say, he is the president of the library organization in much the same way as the president is of the university.

In the last stage of this fictitious but not totally implausible evolution, the university becomes so large that there are only vestiges of a community, though the faculty may stoutly maintain the fiction. Tens of thousands of students are studying (or not studying) all sorts of things and many faculty are engaged in pursuits that have little to do with students at all. The library becomes autonomous at last-it graduates to the status of a research library, that is to say, a library for everyone and for no one. It still acquires most of the books that the faculty want and some that the students want, but in addition it gets a great many that neither want. And it gets a lot of annual report material, for by this time the library has become responsible not only to the so-called academic community but to the university administration. The president of the library reports not to the faculty senate, if there is one, but to the administration of the university. Everyone in the library reports to the director, whom they may see as seldom as a member of an academic department sees the president of the university. Indeed, their predicament is similar, and the faculty may grant the librarians "faculty status" as much in despair as anything else.

The library has become so diffused and the huge collection so various that one gives it, like Santayana's forest, the form one chooses. In fact it has no form other than that of a pile. The pile contains vast bibliographic treasures but maybe as much questionable material as well. At this point the acquisitions program, if there ever was one, breaks down. Some universities come late to the realization that members of the teaching faculty cannot be depended upon to order much except that which immediately interests them. Something the libraries should have realized years and years ago bursts upon them as a revelation. It is taken as proof, not that the acquisitions policy has been foolish, but that one can never adequately anticipate all future needs and programs, so therefore one should buy absolutely as much as possible. But should a library-even a research library-really do that?

While these huge acquisitions programs enable our libraries to collect more and more of what is published, and therefore to build larger and larger stack housings to hold it all, the servicing of the mass has come closer and 
closer to a mockery. Our indexing system is built on the idea of selectivity; our acquisitions system wants to accommodate everything. We believe that each library should have an index to what it owns: a card catalog in most cases, which affords us author and title and subject access to the collection. But it is difficult, if not impossible, to index a pile, especially if the pile keeps getting bigger and bigger, faster and faster, while the personnel to service the pile does not increase at a similar rate.

Two factors affect the indexing of the collection. One is the idea that thorough cataloging presupposes considerable worth (not monetary but intellectual) in the material to be indexed and classified. It follows then that only what is worth cataloging should be cataloged. However, if everything is worthwhile acquiring (who can tell, as Meyer and Demos point out, what will interest the scholars of the future?), then nothing is not worthwhile indexing. When everything is worthwhile the distinction of worthiness no longer exists. Catalogers become discouraged; their work becomes more and more of an exercise in futility. Subject headings become especially stultifying. When one subject heading occupies half a card drawer, it loses most of its usefulness as a subject heading. Indeed, a good bit less than half a drawer of cards, all labeled with the same heading, does not point the user to the specific, but simply tells him that what he wants is not specific enough in this index. The same is true of a classification number; the more books there are under one class number the less useful the number becomes.

The other factor is cost. Libraries which can get greatly increased amounts for book and periodical budgets cannot get enough for personnel. Eventually viciously dishonest talk begins about "increasing the efficiency" of the staff, and most of the methods adopted exacerbate further the quality of catalog- ing. Library of Congress cataloging and classification are accepted no matter how bad they may be; no more than two subject headings to a book no matter how stupid that may be for the indexing of a particular book; no cross-references in the catalog; all devices not to make catalogers more efficient, but simply to make cataloging cheaper in every sense. As the research collection grows the catalog becomes more and more a research catalog-more and more difficult and unrewarding to use.

These factors feed on one another in the manner George Orwell described in his "Politics and the English Language" (available in at least several anthologies) while talking about cause and effect and how the effect strengthens the cause, which then strengthens the effect, and so on back and forth: that is, sloppy thinking makes for sloppy English, which makes for still sloppier thinking, and so on. The messy catalog discourages the cataloger, who is inspired to look away and simply "do his job." The rules are followed perfectly, even though it will often enough make the book more difficult if not almost impossible to find. When a person or group cannot be right, they are all the more likely to withdraw into that cheap substitute, being correct, which is already a temptation to some under the best of circumstances. The catalog becomes more and more discouraging to think about, and the catalogers become less and less committed to it as an index to a collection, but begin to regard it as something containing drawers into which catalog cards are filed. There has been and will continue to be an oversupply of catalogers who view the cata$\log$ in this way: as the repository of correctly done work unrelated to the finding of books and other cataloged material. There is no need for institutional encouragement of such attitudes.

Reference librarians, who should be expert users of libraries, are driven back 
into their reference rooms where they are moved to create a rational collection that can be used well at least by an expert. "Subject" specialties are established in an attempt to cope with the situation. Many reference librarians have discovered that the existence of the job is more important than the existence of a real specialist. One can be transformed into a subject specialist merely by accepting the job with little or no qualification. These specialists in reference and acquisitions often serve in a liaison capacity with the academic departments from which their specialties are copied. The top library administrator has often lost contact with all of the faculty except the politically powerful, and the subject specialists are called upon to establish rapport with the rest. I once heard an odd little speech by an administrator from a large university library, in which the man boasted of the fact that the subject specialists reported directly to the head of the organization. That seemed odd to me, for it should have been a discouraged admission that the library was in an organizational shambles. Nothing better could be done than paste another layer immediately below the top. That hardly reflects rational administration. I might add here that libraries are usually such organizational messes that when something new or different emerges, the solution is often not to work it into the organization, but to tack it or paste it on as a new and separate unit.

The general principle by now ought to be evident: that the more a library becomes a thing unto itself, the less efficient it becomes and the more its operations become a matter of desperate exigency and disordered improvisation. Now in a way this is all sad, but inevitable as far as a research library is concerned. It is doubtful that it is within the powers of library administrators and with our current techniques to do much better. The art of library management is, to say the least, underdeveloped. We can cope pretty well when we know who our public is and what they want, but bigness and the concomitant vagueness undo us.

What is not only sad, but tragic, is that the largest libraries are not only the worst managed but also are often the models of smaller ones which could be managed better. The evidence is all too abundant. If we see an article on library hours it is quite likely that the author will have childishly written off to big brother and asked what his hours are. Should reference librarians be compensated for night and weekend time? Well, what are the big boys doing? If a smaller library is working toward university library status, what should it buy? Why, what the research libraries buy, of course.

Of course. Really? R. L. Stevenson's idea of the sedulous ape is a good one if one is sedulously aping masters; but what about the misdirected ape who is enthusiastically imitating someone who is not doing any better than he is? Or worse?

There should be libraries which are collecting everything, just in case the material should someday become of interest to researchers. But there is very little need for more than a few such libraries. It is true that there is great pressure on academic libraries to get bigger and bigger, for they are judged by little more than the volume count and the size of the book budget. These libraries are forced into becoming gigantic repositories which become more and more difficult to use. It is little wonder that the students at several universities have chosen the card catalog as the object of their resentment; try digging around in one of those things attempting to find something; try to get someone to help you. It is an unhappy accident that the stack tower of one research library I 
have seen looks like a monumental tombstone. It is the book that is buried therein.

Though such be the fate of the large libraries, the smaller ones should not imitate them. Visiting a would-be university library not long ago, I was moved to remark that it looked like an overgrown high school library. Since then I have reflected that it is quite likely that that particular school is indeed an overgrown high school, and that the library may be a most appropriate symbol and efficient tool thereof. A library, especially an institutional one, should be appropriate and sufficient to the present and foreseeable purposes of the institution; not THE COLLEGE or THE UNIVERSITY, but this college, this university. No more, and certainly no less.

But how does one tell what is suffcient, what is adequate? There are, surprisingly enough, a group of faculty present in most libraries who already know or should know. They are the reference librarians (I am one-special pleading, you see) who should all be designated reference librarian and bibliographer (I shudder to mention it, but that is my title). We should be in touch with what the public of this particular library wants and if we are not, we should be damned by that public and the rest of the librarians.

I am inclined to think that the circulation department should be supervised by reference librarian-bibliographers. If not, one should add circulation librarian and bibliographer as the title of another person(s) who should be responsible for building the collection.
We are given to compiling circulation statistics much because it is traditional and makes good annual report material. But we have not made sufficient use of it. We should be milking the circulation files for information on the use that is made of the library and build our collections responsively.

All this, I must admit, would call for a considerable diminution in the autocratic powers of the library administration. The military general staff model will not serve too well, popular though it may be. The model of the factory with its successive layers of management will not fare well either. A functional plan is called for and there are few available models besides the academic department which, though it is not perfect, is closer to what the situation calls for than anything else. If there is anything which stands in the way of such a plan it is the head librarian as LIBRARIAN, writ large.

There is, I think, a real need for the kind of reformation I have suggested here. Things are not as bad as they could be, probably because we are all human. I recall an angry young man telling Judith Krug, director, Office for Intellectual Freedom, ALA, that she was just making things worse for intellectual freedom because she was making it look like the ALA cared by evidencing the fact that she cared. "They don't really carel" he cried, and perhaps he was right. Well, the Judith Krugs in every library (one hopes) ameliorate the situation and that is good, but things could be a lot better and it is in our power to make them so. Why not? 